
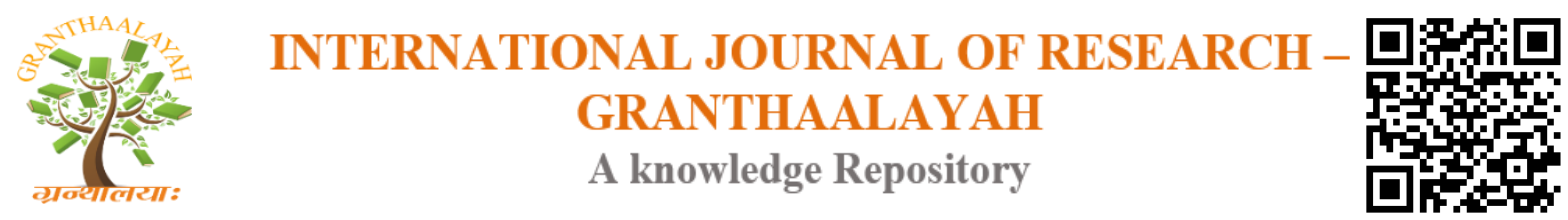

Management

\title{
MODEL FOR AN ALERT UNDER GETTING OEE INTO OLD SHOES OF MC PRICING MECHANISM
}

\author{
Li-Hsing Ho *1, Alang Manglavan ${ }^{2}$, Chung-Cheng Fu *3 \\ ${ }^{* 1,2,3}$ Chung-Hua University, Department of Management, Hsinchu 30012, Taiwan
}

\begin{abstract}
The model for updating marginal cost pricing by overall equipment effectiveness (OEE) indexes as well as $\mathrm{P}^{*} \mathrm{~A}^{*} \mathrm{Q}$ under existing market tough competition.

Motivation/Background: When production capacity is constant and the AC curve is higher than the MC curve, AC pricing can be employed. Because of market competition, businesses producing in small quantities and low diversity use MC pricing. To reduce the risk to profit, a novel cost pricing mechanism can be adopted by using the unit DC of MC to correspond to the OEE under Areeda-Turner Rule.

Method: The correspondence of the OEE with the unit direct cost (DC) is deduced and verified in this paper by calculating the quotient found by dividing the OEE indexes by unit DC as conditional as Bill of Material (BOM) cost.

Results: Research findings revealed a positive alert for timely updating pricing between average cost (AC) pricing and marginal cost (MC) pricing.

Conclusions: This approach reflects the dynamic game in a timely manner. The OEE comprises the performance, availability, and quality indexes. These three indexes reconcile the unit DC pricing, and using $\mathrm{MC}$ in optimization of marginal revenue (MR). In practice, shop floor management measures key indexes of idleness and loss; the objective is to eliminate laggard and static pricing problem. This realizes dynamic examination of cost difference of the BOM cost pool. One case study is employed to explain the MC pricing strategy in industry.
\end{abstract}

Keywords: DC; MC; MR; OEE; BOM.

Cite This Article: Li-Hsing Ho, Alang Manglavan, and Chung-Cheng Fu. (2019). "MODEL FOR AN ALERT UNDER GETTING OEE INTO OLD SHOES OF MC PRICING MECHANISM." International Journal of Research - Granthaalayah, 7(7), 287-296. https://doi.org/10.29121/granthaalayah.v7.i7.2019.766.

\section{Introduction}

When production capacity is constant, the average cost (AC) curve of the economics of scale is higher than the marginal cost curve (Hsu Hwa, 2013), and this is the pricing mechanism of the average business, as illustrated in Fig. 1 (Margetts, 2017). Under the condition of economics of scale, the short-run AC (SAC) and long-run AC (LAC) curves are respectively higher than the 
short-run marginal cost (SMC) curve and long-run MC (LMC) curve. Average businesses employ several versions of the cost accounting method. Using the AC for price setting and using the fixed cost, variable cost, and price floor to determine the pricing mechanism usually result in distorted cost accuracy, leaving a gap in cost pricing. Using full-cost pricing to achieve the most effective profit mechanism entails reconciling the cost structure under biased conditions, and this does not optimize profit for businesses (Noreen and Burgstahler, 1998).

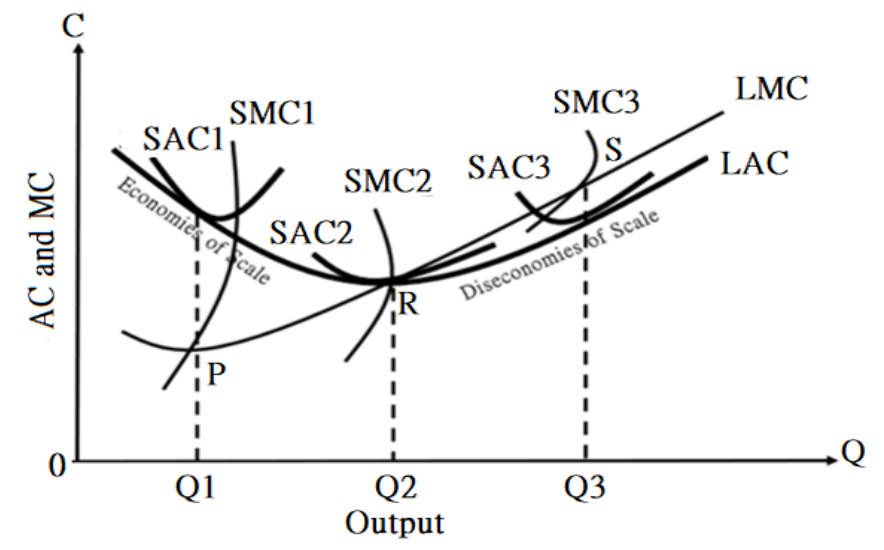

Fig 1 :

RELATIONSHIP BETWEEN SAC \& LAC with SMC \& LMC

Accounting for MCs is statistical social science, whereas accounting for overall equipment effectiveness (OEE) is quantitative natural science. Given considerations to reducing profitmaking risk, the $\mathrm{MC}$ is the additional cost of producing one more unit of a product; the fixed cost is not included, and the variable cost is used as the foundation of pricing. Once the pricing is higher than the variable cost, businesses can obtain a marginal contribution and use it to compensate for the fixed cost (Gramlich and Ray, 2015); the strategy is under Areeda-Turner rule to avoid predatory pricing (Comanor and Frech III, 2015), that is to find the lowest estimate of products, enabling businesses to survive during periods when they are uncompetitive. In the manufacturing industry, the most crucial index offering timely reflective information during production is effectiveness. The OEE is the product of three indexes, namely personnel performance, equipment availability, and product quality; these indexes are also crucial factors for measuring businesses management. Numerous studies have discussed the relevant technical aspects and measurement methods of OEE. However, few studies have discussed mathematical models of MC that can be used to calculate OEE. Using mathematical model OEE to update new pricing mechanism of MC demonstrates the unique feature of a study. Most finance personnel use simple additive weighting (MacCrimmon, 1968) and the AC-sharing methods. MC has replaced AC as the pricing mechanism in markets where the quantity and diversity of products are small. The OEE measurement regulations are displayed in Table 1 (Koch, 2016), and the OEE is the product of performance $\times$ availability $\times$ quality after elimination of time, speed, and quality loss. The correspondence of unit DC under MC with OEE is deduced and verified by dividing the unit DC by the OEE index (MC-OEE= unit DC/OEE). Using mathematical instruments to design a computational model and conduct real practice using an experimental model helps establish a causal relationship and produce internal validity (Blum, 1986). Models are used established based on theories and experiment. This provides the manufacturing industry with an optimized competitive strategy for effective applying MC-OEE pricing. 
Table 1 :

OEE OOE \& TEEP

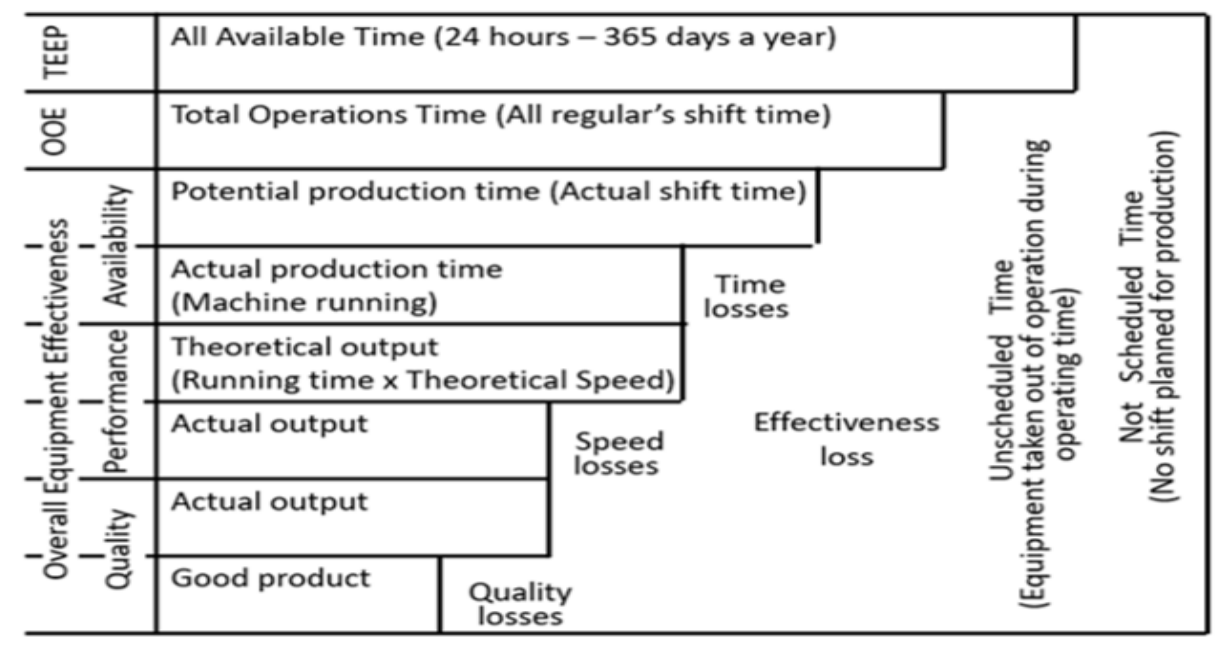

\section{Materials and Methods}

When product capacity is constant, AC pricing is the pricing of accounting. AC pricing, full-cost pricing, and $\mathrm{MC}$ pricing are used to set the price equal to the $\mathrm{AC}$, full cost, and $\mathrm{MC}$, respectively. Because of the law of diminishing marginal productivity, increased production capacity and time cause a shift in dynamic volatility. The SMC curve is lower than the average SAC curve; this characteristic has become the pricing mechanism of the average business (Hsu Hwa, 2013). If production capacity is increased, AC pricing is superior to marginal opportunity cost (MOC) pricing. This is because MOC pricing cannot be associated with a consumer surplus increase (Carter \& Milon, 1992). AC pricing is the price floor constructed by using the LAC as the price platform, but in AC pricing, no consideration is given to the average SAC. The method of computing the LAC and SAC should be redefined. Moreover, their cost structures should be distinguished. To ensure profitability under short-run costs, the fixed allocation rate must be reduced. Short-run AC pricing must respond to market needs to achieve the goals of consumer purchases and profit maximization (OIG, 2013). The goal of the MC pricing strategy is to achieve the lowest sellable price of a product, enabling businesses to survive during times of economic difficulty. Because sunk fixed costs are ignored, the MC pricing strategy enables businesses to theoretically operate without loss (Gramlich and Ray, 2015).

In a hybrid management environment with new and old equipment, businesses optimize their effectiveness in identification, measurement, and decision making to reduce their various losses. These losses include ineffectiveness, low equipment availability, and inconsistent quality. Technology can affect equipment functioning, but high OEE depends entirely on training and implementability (Irhirane et al., 2017). The capital-intensive manufacturing industry invests heavily in precision equipment. Continual investment and the production of different equipment types can be combined using a coherent procedure. The first priority in operation is efficiency. Market orientation is used to respond to the supply and demand relationship of precision computation. Supply chain relationship management is developed to respond to OEE. According to total productivity management and lean maintenance, the space for potential efficiency improvement can be separated into spaces for addressing internal process loss and external market 
demands. For example, reducing the amount of idle equipment, having equipment maintenance periods, and increasing the efficiency of mold upload and download can all contribute to profit maximization (Starr et al., 2010). OEE should reflect the work efficiency, equipment speed, and quality of goods and hence be an indicator of operational performance, indicator of equipment availability, and standardization of quality judgement.

Additionally, OEE should fit meet various needs but be standardized across different industries. This is the optimized decision-making tool for manufacturing (Dal et al., 2000). Using OEE, manufacturing performance can be managed and production equipment maintained to increase profitability. Specifically, OEE is determined in five steps: (1) production equipment check, (2) qualified operator check, (3) production process allocation and classification, (4) total productivity management and lean maintenance implementation, and (5) calculation of the efficiency rate, availability, and quality (Hansen, 2002). Giving consideration to businesses' product quality and customer satisfaction, total quality management and quality function deployment (QFD) were developed in the United States and Japan, respectively. This prompted connection between engineering design, manufacturing, and customer service. The contributions being made by businesses are discovering the voices of customers, identifying the needs of related parties, and meeting those needs (Griffin and Hauser, 1991). The work outcomes of manufacturing management must satisfy internal and external demands and the requirements of employees; additionally, dimensions such as quality, range, time, and cost must be balanced (STPI, 2007). Maximum efficiency is usually defined as the production of maximum satisfaction through investment in each product. In terms of education, the focus of efficiency is to reduce costs and improve learning outcomes (Sage \& Burrello, 1994). Resource loading describes the condition of various resources required by the manufacturing process and personnel within a specific period. All businesses have limited resources, and production must be completed under this constraint, as must manufacturing scheduling. Manufacturing planners and personnel must ensure that customer satisfaction is high through resource allocation and resource leveling. Moreover, further reconcilement can be implemented to enable businesses to allocate resources more effectively.

Resource leveling is also referred to as resource smoothing and balances all the resources required during manufacturing. The purpose of leveling manufacturing resources is to ensure that the resources required throughout manufacturing are relatively constant over time, thereby ensuring robustness in output on the basis of resource availability and manageability. Resource leveling heuristics is a type of network analysis method that determines scheduling by considering resource availability and manageability. When resource over authorization or imbalance occurs, factors such as resource reconcilement and limitation can be considered; additionally, time extensions and communication flexibility can be used to conduct resource leveling and thereby provide the optimal manufacturing equipment and personnel utilization. Resource leveling methods include the float method and task division method. Time paths are usually longer than the original time path when resource leveling is applied (Gilbert, 2013).

A mathematical model that improves the AC is developed in this chapter. The model includes the following performance indexes: personnel operation training, equipment availability, and product quality. Personnel performance is generally limited by the length of training, and operation errors caused by personnel increases the AC. This emphasizes the importance of a performance index's correspondence with the AC. Moreover, when equipment utilization index is essential to product 
effectiveness, understanding the adequate use condition of equipment is crucial. Finally, if the poor quality index is high, its effect on the $\mathrm{AC}$ is stronger.

With changes in workmanship dynamics, QFD responds differently to the personnel performance index, equipment effectiveness index, and quality index. Similarly, the effectiveness index changes according to the learning curve, and consumption is great, small, and smaller in the early, mediumterm, and late stages, respectively; similarly, the performance of some personnel may be poor, good, and excellent in the early, medium-term, and late stages. Detailed information is shown in Table 2, where $p_{i j}$ is the performance index of employee $i$ at stage $j ; a_{i j}$ is the performance index of equipment $i$ at stage $j$; and $q_{i j}$ is the quality index of quality $i$ at stage $j$.

Table 2 :

OEE MODEL

\begin{tabular}{|c|c|c|c|c|}
\hline \multirow{2}{*}{\multicolumn{2}{|c|}{ parameter }} & \multicolumn{3}{|c|}{ Experimental level } \\
\hline & & 1 & 2 & 3 \\
\hline \multirow{3}{*}{$\mathbf{e}_{1}$} & $\mathbf{p}_{1 j}$ & $\mathrm{H}$ & M & L \\
\hline & $a_{1 j}$ & $a_{11}$ & $a_{12}$ & $a_{13}$ \\
\hline & $\mathrm{q}_{1 \mathrm{i}}$ & $\mathrm{q}_{11}$ & $\mathrm{q}_{12}$ & $\mathrm{q}_{13}$ \\
\hline \multicolumn{5}{|l|}{ - } \\
\hline \multirow{2}{*}{\multicolumn{2}{|c|}{ parameter }} & \multicolumn{3}{|c|}{ Experimental level } \\
\hline & & 1 & 2. & 3 \\
\hline \multirow{3}{*}{$\mathbf{e}_{2}$} & $\mathbf{p}_{2 j}$ & L. & $\mathbf{M}$ & $\mathrm{H}$ \\
\hline & $a_{2 j}$ & $a_{21}$ & $a_{22}$ & $a_{23}$ \\
\hline & $q_{2 j}$ & $\mathrm{q}_{21}$ & $\mathrm{q}_{22}$ & $\mathrm{q}_{23}$. \\
\hline \multirow{2}{*}{\multicolumn{2}{|c|}{ parameter }} & \multicolumn{3}{|c|}{ Experimental level } \\
\hline & & 1 & 2 & 3 \\
\hline \multirow{5}{*}{$e_{3}$} & $\mathrm{p}_{3 j}$ & L. & M & M \\
\hline & $a_{3 j}$ & $a_{31}$ & $a_{32}$ & $a_{33}$ \\
\hline & $\mathrm{q}_{3 j}{ }^{*}$ & $\mathrm{q}_{31}$. & $\mathrm{q}_{32}$ & $\mathrm{q}_{33}$ \\
\hline & Index & $\left(\mathrm{OEE}_{1}+\mathrm{OEE}_{2}\right.$ & $\left(\mathrm{OEE}_{1}+\mathrm{OEE}_{2}\right.$ & $\left(\mathrm{OEE}_{1}+\mathrm{OEE}_{2}\right.$ \\
\hline & & $\left.+\mathrm{OEE}_{3}\right) / 2.85$ & $\left.+\mathrm{OEE}_{3}\right) / 2.85$ & $\left.+\mathrm{OEE}_{3}\right) / 2.85$ \\
\hline
\end{tabular}

Production orders are separated into three batches - e1, e2, and e3 - and each batch was separated into stages $1-3$. The sum of the maximum value of the indexes is $0.95+0.95+0.95=2.85$. The index of product OEE importance is determined using the operational performance, equipment availability, and quality indexes. The mutual contagion model of the three crucial OEE indexes corresponds to the ultimate key index of OEE.

The objective of this study is to construct a mathematical model that includes all the aforementioned factors. A model for calculating the optimal AC can be constructed as

$\operatorname{Max} O_{i}=\sum_{j=1} \sum_{j=1} \sum p j q_{i j}$

S.T. $W_{i}=K / \sum_{j=1} a_{i j} \quad i=1 \ldots m$ 
$\sum_{i=1}^{m} w_{i} \leq w$

$q i j=f\left(a_{i j}\right)$

$0 \leq a_{i j} \leq z_{i}$

where $O$ is the OEE;

$k$ is the unit DC;

$W_{i}$ is the corresponding index of SMC;

and $w$ is upper limit of the corresponding index of SMC.

\section{Results and Discussions}

The effectiveness of the model proposed in this study is illustrated using a case study. The hypothetical production order of SMC can be separated into three stages. Additionally, a production order has three batches (e1-e3). The indexes and changing index for each production order in the three stages are displayed in Table 3.

The OEE of performance indexes for the three stages of a production order is calculated, as shown in Table 3. The performance and validity of the OEE changes according to the production order batch. In production order e1, the OEE is relatively high, lower, and even lower in the early, medium-term, and late stages, respectively. In production order e2, the OEE is relatively low, relatively high, and even higher in the early, medium-term, and late stages, respectively. Finally, in production order e3, the OEE is low in the early stage and equally high in the medium-term and late stages. Numerical analysis of the OEE shows that the performance of e1 in the early stage is $\mathrm{P} 11=0.95$, medium-term stage is $\mathrm{P} 12=0.9$, and late stage is $\mathrm{P} 13=0.85$. The corresponding values for $\mathrm{e} 2$ are $\mathrm{P} 21=0.85, \mathrm{P} 22=0.9$, and $\mathrm{P} 23=0.95$ and for $\mathrm{e} 3$ are $\mathrm{P} 31=0.8, \mathrm{P} 32=0.9$, and $\mathrm{P} 33=0.9$.

Table 3 :

OEE MODEL for CASE STUDY

\begin{tabular}{|c|c|c|c|c|}
\hline \multirow{2}{*}{\multicolumn{2}{|c|}{ parameter }} & \multicolumn{3}{|c|}{ Experimental level } \\
\hline & & 1 & 2 & 3 \\
\hline \multirow{3}{*}{$e_{1}$} & $\mathbf{p}_{1 j}$ & $\mathrm{H}(0.95)$ & $\mathrm{M}(0.9)$ & $\mathrm{L}(0.85)$ \\
\hline & $a_{1 j}$ & $a_{11}$ & $a_{12}$ & $a_{13}$ \\
\hline & $\mathrm{q}_{1 \mathrm{i}}$ & $\mathrm{q}_{11}$ & $\mathrm{q}_{12}$ & $\mathrm{q}_{13}$ \\
\hline \multicolumn{5}{|l|}{ 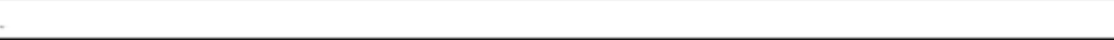 } \\
\hline \multirow{2}{*}{\multicolumn{2}{|c|}{ parameter }} & \multicolumn{3}{|c|}{ Experimental level } \\
\hline & & 1 & 2 & 3 \\
\hline \multirow{3}{*}{$e_{2}$} & $\mathbf{p}_{2 j}$ & $L(0.85)$ & $M(0.9)$ & $\mathrm{H}(0.95)$ \\
\hline & $\mathbf{a}_{2 j}$ & $a_{21}$ & $a_{22}$ & $a_{23}$ \\
\hline & $\mathbf{q}_{2 j}$ & $\mathrm{q} 21$ & q22. & $\mathrm{q} 23$ \\
\hline \multirow{2}{*}{\multicolumn{2}{|c|}{ parameter }} & \multicolumn{3}{|c|}{ Experimental level } \\
\hline & & 1 & 2 & 3. \\
\hline \multirow{5}{*}{$e_{3}$} & $\mathrm{p}_{3 j}$ & $L(0.8)$ & $\mathrm{M}(0.9)$ & $\mathrm{M}(0.9)$ \\
\hline & $a_{3 j}$ & $a_{31}$ & $a_{32}$ & $a_{33}$ \\
\hline & $\mathrm{q}_{3 j}$ & $\mathrm{q} 31$ & $\mathrm{q} 32$ & $\mathrm{q} 33$ \\
\hline & Index & $\left(\mathrm{OEE}_{1}+\mathrm{OEE}_{2}\right.$ & $\left(\mathrm{OEE}_{1}+\mathrm{OEE}_{2}\right.$. & $\left(\mathrm{OEE}_{1}+\mathrm{OEE}_{2}\right.$ \\
\hline & & $\left.+\mathrm{OEE}_{3}\right) / 2.85$ & $\left.+\mathrm{OEE}_{3}\right) / 2.85$ & $\left.+\mathrm{OEE}_{3}\right) / 2.85$ \\
\hline
\end{tabular}


Following analysis of the aggregative index in Table 3, the parameters were set as $k=10, w=20$, $q_{i j}=a_{i j}{ }^{2}-a_{i j}+$ index, $\mathrm{P}_{11}=0.95, \mathrm{P}_{12}=0.9, \mathrm{P}_{13}=0.85, \mathrm{P}_{21}=0.85, \mathrm{P}_{22}=0.9, \mathrm{P}_{31}=0.85, \mathrm{P}_{32}=0.9$, $\mathrm{P}_{33}=0.9, p_{j}=1$ and substituted into Equation (1), obtaining the following overall model:

Max $\mathrm{k} /\left(\mathrm{q}_{11} * \mathrm{q}_{12} * \mathrm{q}_{13}\right)+\left(\mathrm{q}_{21} * \mathrm{q}_{22} * \mathrm{q}_{23}\right)+\left(\mathrm{q}_{31} * \mathrm{q}_{32} * \mathrm{q}_{33}\right)$

S.T. $\quad \mathrm{W}_{1}=\mathrm{k} /\left(\mathrm{a}_{11} * \mathrm{a}_{12} * \mathrm{a}_{13}\right)$

$\mathrm{W}_{2}=\mathrm{k} /\left(\mathrm{a}_{21} * \mathrm{a}_{22} * \mathrm{a}_{23}\right)$

$\mathrm{W}_{3}=\mathrm{k} /\left(\mathrm{a}_{31} * \mathrm{a}_{32} * \mathrm{a}_{33}\right)$

$\mathrm{W}_{1}+\mathrm{W}_{2}+\mathrm{W}_{3}<=50$

p11 $=0.95$;

p12 = 0.9;

$\mathrm{p} 13=0.85$;

$\mathrm{p} 21=0.85$

p22 = 0.9;

$\mathrm{p} 23=0.95$;

$\mathrm{p} 31=0.85$

$\mathrm{p} 32=0.9$

p33 = 0.9;

$\mathrm{q}_{11}=\mathrm{a}_{11}{ }^{2}-\mathrm{a}_{11}+0.95$

$\mathrm{q}_{12}=\mathrm{a}_{12}{ }^{2}-\mathrm{a}_{12}+0.9$

$\mathrm{q}_{13}=\mathrm{a}_{13}{ }^{2}-\mathrm{a}_{13}+0.8$

$\mathrm{q}_{21}=\mathrm{a}_{21}{ }^{2}-\mathrm{a}_{21}+0.85$

$\mathrm{q}_{22}=\mathrm{a}_{22}{ }^{2}-\mathrm{a}_{22}+0.9$

$\mathrm{q}_{23}=\mathrm{a}_{23}{ }^{2}-\mathrm{a}_{23}+0.8$

$\mathrm{q}_{31}=\mathrm{a}_{31}{ }^{2}-\mathrm{a}_{31}+0.85$

$\mathrm{q}_{32}=\mathrm{a}_{32}{ }^{2}-\mathrm{a}_{32}+0.9$

$\mathrm{q}_{33}=\mathrm{a}_{33}{ }^{2}-\mathrm{a}_{33}+0.8$

$0.8<\mathrm{a}_{11}<=0.95$

$0.8<\mathrm{a}_{12}<=0.95$

$0.8<\mathrm{a}_{13}<=0.9$

$0.8<\mathrm{a}_{21}<=0.9$

$0.8<\mathrm{a}_{22}<=0.9$

$0.8<\mathrm{a}_{23}<=0.9$

$0.8<\mathrm{a}_{31}<=0.85$

$0.8<\mathrm{a}_{32}<=0.95$

$0.8<\mathrm{a}_{33}<=0.95$

End

By using Lingo to seek solutions, the maximum OEE of 25.81 is obtained. The performance index, effective index, quality index, and overall index at each stage are listed in Table 4. The OEE is $0.59,0.67$, and 0.66 in the early, medium-term, and late stages, respectively. 
Table 4 :

OEE MODEL

\begin{tabular}{|c|c|c|c|c|}
\hline \multirow{2}{*}{\multicolumn{2}{|c|}{ parameter }} & \multicolumn{3}{|c|}{ Experimental level } \\
\hline & & 1 & 2 & 3 \\
\hline \multirow{3}{*}{$\mathbf{e}_{1}$} & $\mathbf{p}_{1 j}$ & $\mathrm{H}(0.95)$ & $M(0.9)$ & L.(0.85) \\
\hline & $\mathbf{a}_{1 j}$ & 0.8 & 0.8 & 0.8 \\
\hline & $\mathbf{q}_{1 j}$ & 0.79 & 0.74 & 0.69 \\
\hline \multicolumn{2}{|l|}{$\mathrm{OEE}_{1}$} & 0.60 & 0.53 & 0.47 \\
\hline \multicolumn{2}{|l|}{$\mathbf{W}_{1}$} & & 19.53 & \\
\hline \\
\hline \multirow{2}{*}{\multicolumn{2}{|c|}{ parameter }} & \multicolumn{3}{|c|}{ Experimental level } \\
\hline & & 1 & 2 & 3. \\
\hline \multirow{3}{*}{$\mathbf{e}_{2}$} & $\mathbf{p}_{2 j}$ & L. (0.85) & $\mathrm{M}(0.9)$ & $\mathrm{H}(0.95)$ \\
\hline & $\mathbf{a}_{2 j}$ & 0.9 & 0.9 & 0.9 \\
\hline & $\mathbf{q}_{2 j}$ & 0.76 & 0.81 & 0.86 \\
\hline \multicolumn{2}{|c|}{$\mathrm{OEE}_{2}$} & 0.58 & 0.66 & 0.74 \\
\hline \multicolumn{2}{|l|}{$\mathrm{w}_{2}$} & & 13.72 & \\
\hline \multirow{2}{*}{\multicolumn{2}{|c|}{ parameter }} & \multicolumn{3}{|c|}{ Experimental level } \\
\hline & & 1 & 2 & 3 \\
\hline \multirow{3}{*}{$\mathbf{e}_{3}$} & $\mathbf{p}_{3 j}$ & $\mathrm{~L}(0.8)$ & $\mathrm{M}(0.9)$ & $M(0.9)$ \\
\hline & $\mathbf{a}_{3 j}$ & 0.85 & 0.95 & 0.9 \\
\hline & $\mathbf{q}_{3 j}$ & 0.72 & 0.85 & 0.81 \\
\hline \multicolumn{2}{|c|}{$\mathrm{OEE}_{3}$} & 0.49 & 0.73 & 0.66 \\
\hline \multicolumn{2}{|l|}{$\mathbf{w}_{3}$} & & 13.76 & \\
\hline
\end{tabular}

Because the OEE reflects the bill of unit DC, these values indicate that costs of the first, second, and third batches were 19.53,13.72, and 13.76, respectively. These costs correspond to the costs in real operations. Following explanation of production order separation batches from a practical perspective, the OEE of each batch indicates the indexes displayed in Fig. 2. OEE1 is 0.6, 0.53, and 0.47 , and the unit actual cost is $\mathrm{W} 1=19.53$, higher than the set value of direct cost, $k=10$. OEE2 is $0.58,0.66$, and 0.74 , and the unit actual cost is $\mathrm{W} 2=13.72$, higher than the set value of direct cost, $k=10 . \mathrm{OEE}_{3}$ is $0.49,0.73$, and 0.66 , and the unit actual cost is $\mathrm{W} 3=13.76$, higher than the set value of direct cost $k=10$, as illustrated in Fig. 3. In practice, the cost pool is reconciled with the dynamics of performance, and a lower OEE corresponds to a higher cost and greater deviation from MC pricing.
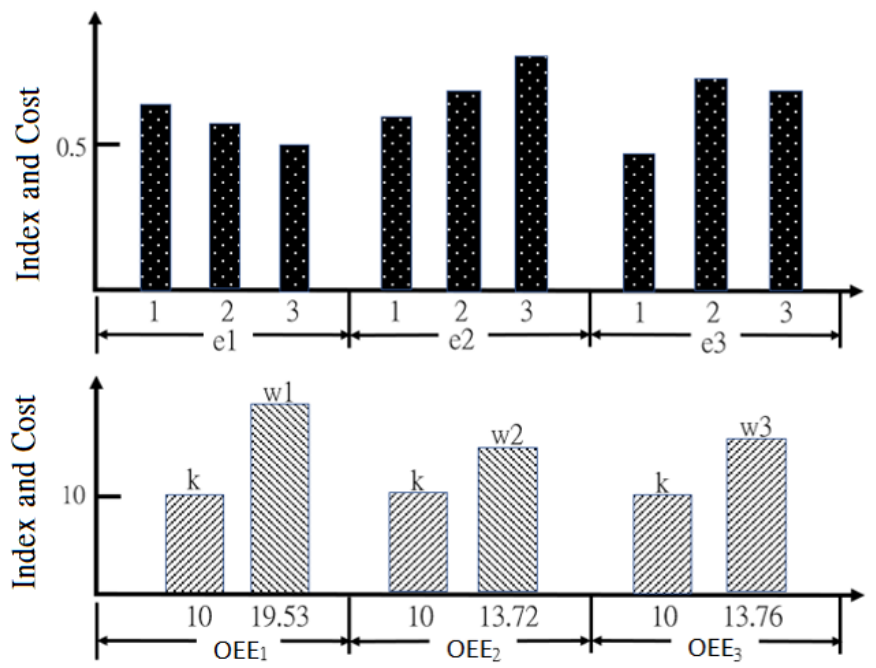

Fig. 2 :

INDEX VERSUS COST 


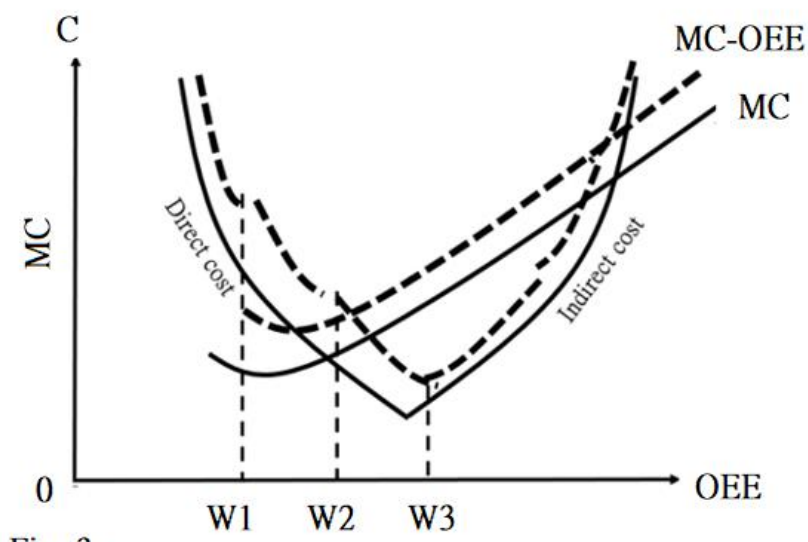

Fig. 3 :

W1 W2 W3

COST RELATIONSHIP BETWEEN MC AND MC-OEE

\section{Conclusions and Recommendations}

In a perfectly competitive market, the fundamental reason for increasing the $\mathrm{MC}$ is the diminishing marginal product. The short-term balance condition for firms is MR $=\mathrm{MC}$. Conditions of longterm balance in firms in a perfectly competitive market exist within short time periods. Although firms facing perfect competition can achieve balance, they cannot adjust production size and may experience losses to achieve short-term OEE balance when the production capacity is constant. When the scale is small and diversity of production is low, the production capacity of business equipment is not adequately used. The production function increases at an incremental rate as the inputs are increased. At this stage, the rate of production increase exceeds the rate of cost increase. Consequently, the MC decreases as production capacity increases. When the number of employee reaches a certain level, the business becomes crowded. At this point, every additional employee increases the utilization rate of the production equipment, but this increase in utilization rate decreases gradually until the economics of scale are lost.

The OEE should be improved to enhance the performance index, availability index, and quality index. These three indexes reflect the human and machine idle time, waiting time, and losses incurred by defective goods. The unit DC of MC corresponds to the OEE, and the objective is to determine increases and decreases in the OEE for different departments and products in a timely manner. This prevents arbitrary allocation of illogical costs in the unit direct and indirect costs. Simple calculation can be used to understand and reconcile the MC pool with the OEE, thereby obtaining profitable MC-OEE pricing that correspond to the OEE. Accordingly, business profit can be optimized.

\section{References}

[1] Anna, P. Della Valle. (1988). Short-run versus long-run MC pricing. Elsevier Volumn 10, Issue 4, Page 283-286

[2] Blum, B.L. (Ed.) (1986). Clinical information systems. New York, NY: Springer.

[3] Braeutigam, Ronald R. (1980)."An Analysis of Fully Distributed Cost Pricing in Regulated Industries." Bell Journal of Economics 11 (1980): 182-196.

[4] Comanor, William S. and H.E. Frech III. (2015, March 6). Economic Rationality and the AreedaTurner Rule. UC Santa Babara, Permalink https:// escholarship.org/uc/item/ 7vq8v499 
[5] Carter, W. David, and J. Walter Milon. (1999). Marginal Opportunity Cost vs. AC Pricing of Water Service: Timing Issues for Pricing Reform, https://pdfs. semanticschalar.org

[6] Dal, Bulent, Phil Tugwell, and Richard, Greatbanks. (2000). Overall equipment effectiveness as a measure of operational improvement - A practical analysis. International Journal of Operations \& Production Management. New Zealand.

[7] Gilbert, Kalila. (2013). PMBOK 5th Edition. Project Management Institute, Inc. U.S.A.

[8] Gramlich, P. Jacob and Korok Ray. (2015). Reconciling Full-Cost and MC Pricing. Finance and Economics Discussion Series Divisions of Research \& Statistics and Monetary Affairs Federal Reserve Board, Washington, D.C. U.S.A.

[9] Griffin, Abbie and John Hauser. (1991). The Voice of the Customer. John Wiley \& Sons Ltd. U.S.A.

[10] Gupta, K. Amit, R. K. Garg. (2012). OEE Improvement by TPM Implementation: A Case Study. IJISEAR Volumn 1, No. 1

[11] Hansen, Robert C. (2002). Overall equipment effectiveness: a powerful /production/ maintenance tool for increased profits. Industrial Press. NY. U.S.A.

[12] Hsu, Hwa. (2013). Ntural monopolized pricing - either MCing or ACing. China Academic Journal Publishing House, China

[13] Irhirane, Elhassan, Ahmed Bounit and Badr Dakkak. (2017). Estimate of OEE (Overall Equipment Effectiveness) Objective from Classical OEE. International Journal of Performability Engineering, Vol. 13, pp. 135-142. Totem Publisher, Inc., Texas 75024, U.S.A

[14] Koch, Arno. (2016). OEE Coach: Answer Your OEE Questions to find-, visualize and employ the hidden machines in your factory; to turn your Iron into Gold. OEE Coach, Powered by Mantra \& WordPress, Netherlands

[15] Macrrimmon, Kenneth R. and Donald A. Wehrung. (1986). Taking Risks: The Management of Uncertainty, Free Press, New York

[16] Margetts, Steve. (2017). Short Run and Long Run. Revision Guru, www.revisionguru.co.uk

[17] Noreen, W. Eric. and Burgstahler. (1998). Full Cost Pricing and the Illusion of Satisficing. Journal of Management Accounting Research, Seattle, WA U.S.A.

[18] OIG. (2013). Short-Run Costs and Postal Pricing, U.S. Postal Service Office of Inspector General, RARC-WP-13-004, U.S.A

[19] Sage, Daniel D. and Leonard C. Burrello. (1994). Leadership in Educational Reform: An Administrator's Guide to Changes in Special Education. Paul H. Brookes Publishing Co. MD, U.S.A.

[20] Starr, Andrew, Farhad Anvari and Rodger Edwards. (2010). Evaluation of overall equipment effectiveness based on market. Journal of Quality in Maintenance Engineering, V. 16, issue 3. U.K.

[21] STPI. (2007). Internal and External under Production and Management. STPI Taiwan. http://iknow.stpi.narl.org.tw

\footnotetext{
*Corresponding author.

E-mail address: mark.c.fu@ gmail.com
} 